\title{
COMPETENCE MODEL FOR MEASURING CAREER DEVELOPMENT AND ORGANISATIONAL GROWTH IN THE HEALTH SECTOR
}

\author{
Anthonia ADENIJI ${ }^{1}$, Omotayo OSIBANJO ${ }^{2}$, Odunayo P. SALAU ${ }^{3}$, Hezekiah O. FALOLA ${ }^{4}$, \\ Ebegbuki IGBINOBA ${ }^{5}$, Folakemi OHUNAKIN ${ }^{6}$, Opeyemi OGUEYUNGBO ${ }^{7}$
}

\author{
Covenant University, Ota, Nigeria \\ E-mails: ${ }^{1}$ anthonia.adeniji@covenantuniversity.edu.ng (corresponding author); \\ 2ade.osibanjo@covenantuniversity.edu.ng; ${ }^{3}$ odunayo.salau@covenantuniversity.edu.ng; \\ ${ }^{4}$ hezekiah.falola@covenantuniversity.eddu.ng; ${ }^{5}$ ebegbuki.igbinoba@covenantuniversity.edu.ng; \\ ${ }^{6}$ folakemi.ohunakin@stu.cu.edu.ng; ${ }^{7}$ opeyemi.ogueyungbo@covenantuniversity.edu.ng
}

Received 31 October 2018; accepted 18 February 2019

\begin{abstract}
The present changing trend and competitive business world have compelled many sectors to improve their service quality, productivity and performance. The health sector is a unique sector with peculiar work environment and developmental expectations from workers of different categories. Experts indicate that the Nigeria health sector budget is not impressive as it has never moved closer to World Health Organization template of $15 \%$ of the annual budget allocated to the health sector. Arising from this gross underfunding, the health sector has become weak while infrastructure and logistic supports seem to be obsolete with defective career initiative programmes. Hence, the present study assessed a competence model for measuring career development and growth of the health sector in Nigeria. The descriptive research design was adopted using stratifiedrandom sampling technique with a mixed method (specifically, sequential explanatory method) approach for gathering data from the selected teaching hospitals. Six dimensions and 30 item statements of career development and organizational growth have been adopted from previous studies. The use of a structured questionnaire was employed and completely filled by 377 staff and management of the selected tertiary institutions. Data collected through the copies of questionnaire were analysed through measurement and structural models (SEM_PLS3); while interview data were codified and themes extracted. The results of the statistical analysis reveal that organizational growth significantly depends not only on the formulation and implementation of career development programmes but also on monitoring. The findings of this research have explicit implications for both the employees and the organizations. This study suggests that management will need to provide interventions and be more active in carefully implementing career management plans that will meet individual and organizational goals.
\end{abstract}

Keywords: career development, organisational growth, skills, promotion, efficiency, satisfaction.

JEL Classification: M1, M5, M54.

\section{Introduction}

Across the globe, one of the major obstacles to the achievement of high productivity and organisational effectiveness is the level of career development. Employees are the central fulcrums of all socio-economic activities and they are the basic factor for success or failure of the organization. It is on the basis of this, that most modem organizations who recognise that their employees are their most valuable assets have focused their attention on organizational approaches/ managerial desiderata aimed at attracting and retaining dedicated, loyal, highly motivated, energetic, creative and well-trained workforce needed to accomplish organisational goals (Adeniji et al. 2017). An approach, which is a panacea to this managerial need, is the implementation of career development process (Adeniji et al. 2018).

Within many sectors, especially, in health sector worldwide, increased attention is being focused on human resource management (HRM) practices which include career development, human capital development, talent attraction and acquisition, compensation, wages and salaries

Copyright @ 2019 The Authors. Published by VGTU Press.

This is an Open Access article distributed under the terms of the Creative Commons Attribution License (http://creativecommons.org/licenses/by/4.0/), which permits unrestricted use, distribution, and reproduction in any medium, provided the original author and source are credited.. 
administration, succession planning, etc. The health sector is a unique sector with peculiar work environment and career development expectations from workers of different categories. Career development has become a critical aspect of HRM practices and examines how individuals in the organizations move up their career ladders (Osibanjo et al. 2014, Mishra and Sachan 2012, Lam et al. 2013).

Every company promotes itself by offering great career progression. Yet research shows that $70 \%$ of employees are dissatisfied with future career opportunities in their organization (Bombuwela and Alwis 2013, Adeniji et al. 2014, Salau et al. 2014). A lack of future career opportunities is the primary driver of employee attrition (Sheppard 2016, Brousseau et al. 2012, Adeniji and Osibanjo, 2012). Career development is a lifelong learning process (Tareef 2012, Sahoo and Mishra 2012) and it involves continuous development (Maimunah and Atikah 2016, Adenij et al. 2017) for regulating work, life and learning. Based on the Bull's eye model, employees are said to be more satisfied and productive in their work when their skill, values, abilities, personality and interest align with their career choice. Therefore, when employees in organizations experience progress in their line of work in an organization they become committed and want to stay in the organization since they perceive that their personal career goals and aspirations are likely to be achieved in that firm, they stay when they feel that their future can blossom in the organization without being stagnated in life (Ohunakin et al. 2018a). Flexer et al. (2005) has identified that all the career stages are not necessarily observed at once in career life of a person but can occur at various times as a result of varied changes in career e.g. changing of job.

The health sector of the Nigeria's economy is statutorily established to provide essentially health care services to Nigerians irrespective of their locations within the territorial jurisdiction. In short, the health care delivery services in Nigeria, as well as the National Health Policy, aimed at addressing the provision of intensive, effective and efficient health care services to the people of Nigeria in order to allow them achieve laudable goals of health standard such that everyone enjoy life at all levels of human endeavor. But despite the fulfilment of the objectives, the sector is still faced with some critical and ever-emerging problems. Arising from the gross underfunding of the health sector institutions is the weak, obsolete and defective infrastructure and logistic supports (Zin et al. 2013, Ovidiu 2013, Mishra and Sachan 2012). This is due to inadequate maintenance of buildings, medical equipment and vehicles, shortage of drugs, faulty compounding of drugs, poor management of drugs, the expiry of drugs and vaccines and other essential requirements for patients care. The utility Boards in Nigeria often make the problem worse by engaging in irregular supply of water, erratic or rather epileptic supply of electricity and poor telecommunication services.
The Nigeria health sector budget is not impressive as it has never moved closer to World Health Organization template of $15 \%$ of the members' annual budget to be allocated to the health sector. This recalcitrant act of the Nigeria Governments, past and present is inimical to health care infrastructural development and save delivery services. It affects so many units of health development. The poor health financing arising from lean budget often results in weak and obsolete infrastructure in the hospitals, congestion of patients to access health care because of limited human resources, poor supply of water, wards congestion, irregular supply of electricity, weak telemedicine facility and recruitment, training and retraining of staff of hospitals etc. The review of literature shows a significant amount of management research on career planning, expansion, career planning, and career exploration for improving employees' career motivation and commitment, although many observers still regard these variables as organizational activities and strategies that largely benefit firms, employees and societies. Thus, consistent measures for engaging and implementing career development practice often remain unacknowledged. Although few researchers (Adeniji and Osibanjo 2012, Salau et al. 2014, Mishra and Sachan 2012, Lam et al. 2013) have tried to link career management with competitive advantage from a strategic management perspective, they have failed to explain the mechanisms about how career management activities can be helpful beyond average returns. Therefore, this survey addressed the effects of the independent (career development) variables on the dependent variable of organizational growth in transition economy and in particular selected teaching hospitals, Nigeria.

To investigate the relationships, the following research objectives were formulated:

1. To assess the predictor importance of the competence model for measuring career development

2. To ascertain the impact of leadership domain on the growth of selected teaching hospitals

3. To examine the influence of intrapersonal domain on the growth of selected teaching hospitals

4. To analyse the joints contributions of career development measures on the growth of selected teaching hospitals

\section{Review of literature}

Employees play a pivotal role in every industrial organization. In managing people's talent, abilities, and capabilities, organizations strive to gradually develop strategies for embracing career development. Career development play vital role in improving and nurturing competencies in a way that it has helped in the fulfilment of organizational objectives (Adeniji et al. 2018, Ibidunni et al. 2016, Mishra and Sachan 2012). Career development is seen as a process of providing employees with opportunities and allowing 
them reach their full potentials through enhancing their abilities, knowledge, skills and capabilities (Armstrong 2011, Tareef 2012). Career development is part of HRM practices which is known as the process by which managers encourage and motivate employees to be accountable for their own careers and provide continuous support for career opportunities (Ohunakin et al. 2017, Zhang 2012). According to Maimunah (2016), career development consists of training, coaching, mentoring, counselling and promotion to stimulate the performance of employees. Furthermore, with continued career progression, employees are motivated to learn the skills and knowledge needed for career advancement. There is a strong academic consensus that HR managers must consistently and certainly have more "conversations" with their staff but unfortunately, the health-care organizations seem to have discouraged the essentially human habit of using discussions to find out what is going on, resolve issues, get advice, give encouragement and agree what we need to do.

Upward movement has been labelled as a difficult aspect in most sectors, including the tertiary health care subsector. As organisations grow, inevitably systems and processes are needed to keep things efficient and to scale up. Health care is a different environment and different factors apply when it comes to upward mobility (Sheppard 2016, Tareef 2012, Vander-Sluis and Poell 2003). Hence, it will be said that the success or failure of any organizations depends on the growth of the employees in the organization. Organizational growth can be seen as one of the indicators of effectiveness for businesses and it is a critical issue for many practicing managers. The term organizational growth, however, means different things to different organizations. Organizations have developed several parameters for measuring its growth. Since the main goal of any business is to increase the profit margin, most firms measure their growth in terms of net profit, revenue, sales growth, size of the employees, physical expansion, or increased market share (Rostami et al. 2015, Salau et al. 2018).

\subsection{Career development and organizational growth}

With growing longevity, employees are expected to develop new skills or even to build new careers. And the velocity of change in business models and technology means not only that, but also their employers, need to evolve their skills and knowledge. Many previous studies used the antecedent variables such as management support, psychological justice, workers' empowerment, leadership and organizational culture (Ohunakin et al. 2018b, Zin et al. 2013, Oni-Ojo et al. 2015, Ibidunni et al. 2016) to influence organizational growth especially in the perspective of productivity, profitability, and commitment. There are also researches that investigated the relationship between the determinant of career development and employees' performance (Oduma and Were 2014, Osibanjo et al. 2018). The role of career development as an independent variable in this relationship is very important because this activity contributes to skills, knowledge, ability, attitude and motivation enhancement that able to increase employees' performance at work place.

The impact of career development on firm' performance has been examined by many studies in different perspective. For example, a study by Wahyuni (2016) used sample of 90 employees in health sector, Gowa, Indenesia. Oduma and Were (2014) used 487 sample of employees working in Kenyatta Teaching University, Kenya and a study by Merchant Jr (2010) involved 100 sample of health workers revealed that career development that includes training, coaching and counselling had been a main predictor of their performance. Another study was also conducted by Osibanjo et al. (2014) on career development and organizational growth. The result sees career development as a major determinant of organizational growth. Just like in the contemporary organizations, the employees of various sector cherish and espouse career growth and development; and the management of the sectors have orchestrated different programmes and policies to encourage career growth and goal attainment, motivate and enhance employee performance (Adekola 2011, Tareef 2012, Adeniji and Osibanjo 2012, Osibanjo et al. 2014, Salau et al. 2018). The question emanating from this management initiative is; has the opportunity for career development encouraged growth in the tertiary healthcare sector?

Tertiary healthcare facilities are referral centers receiving referrals from secondary and primary healthcare centres. In Nigeria, the Federal Government has 20 teaching hospitals, 22 Federal Medical Centres and 13 specialist hospitals, making a total of 55. In terms of access, this is inadequate to serve a nation of about 170 million people even when the hospitals owned by the state governments are added. With public enlightenment on the radio, television and newspapers on the activities of the National Health Scheme (NHS) more patients are visiting tertiary hospitals where they pay very little or nothing to receive healthcare. This has increased patient admissions and more pressure is exerted on the available facilities leaving them to yearn for more personnel and upward mobility. As a result, more and more Nigerians are flocking overseas for medical treatment, seeking to escape the worsening and worrisome health services. The private hospitals are many, but they equally lack the equipment, resources and personnel, and are mostly located in the urban centres. As our population rapidly grew, the government neglected the emerging dynamics. According to the Nigerian Medical Association (NMA), there are 40,000 Nigerian medical doctors, but 19,000 out of them are practising abroad, while 70 per cent operate in "urban centres where 30 per cent of the population reside." This is a dismal ratio. As a result, the World Health 
Organisation classifies the country among the 44 per cent of nations that have less than one per cent of physiciansper-1000 population. While Oladejo (2014) in a study of tertiary healthcare institutions in South East Nigeria observed that the sector lacks adequate number of personnel, consistent training and career development programmes. Kalejaiye et al. (2015) also indicated that the present caliber of staff is obviously not enough to attend to the volume of patients that are patronizing them, while inconsistent upward mobility has also contributed to job dissatisfaction of staff and incessant strikes to press home their demands at every turn.

\subsection{Theoretical underpinnings}

This study was anchored on social exchange theory developed by Blau (1964). This theory demonstrated that organizational growth may be enhanced when employees have belief and satisfaction on the career development practice in organization. While, according to Maslow's Hierarchy of Needs Theory (1970), the employees will be motivated and they will struggle for the organization interests when their needs are prioritized by the management such as close monitoring activities and promotion opportunity provided in career development human resource management. The essence and benefit of the theory to the employees' performance research framework is the employees' effectiveness can be performed if the management solves immediate problems including career development aspect and prioritize reward performance (Law and Watts 2015, Sultana 2013). As a result, the employees will have more confidence to their organization and they will be more effective in doing their jobs when a proper practice of career development gives significant impact to their needs and ambitions.

\section{Methodology}

The population in this investigation consist lower to toplevel management employees that are performing their duties in the health sector, specifically, the teaching hospitals in Nigeria. In Nigeria, the Federal Government has 20 teaching hospitals, 22 Federal Medical Centres and 13 specialist hospitals, making a total of 55 . Hence, this study focused on the teaching hospitals and two (Lagos State University Teaching Hospital (LASUTH) and University College Hospital [UCH], Ibadan). selected tertiary healthcare hospitals with the highest number of in and out patient visits to the hospitals. The selected teaching hospitals have emerged as the oldest and most researched/ patronised teaching hospitals in Nigeria (Nairaland 2018, Oladejo 2014). Indicators of the strength of teaching hospitals include: patients relationship management, service quality, nurses/doctors retention rate, heightened facilities, drugs and facilities availability, etc. In addition, convenience sampling technique was used for data collection, which is called non-probabilistic sampling type.

Descriptive (survey) research design using mixed method (sequential explanatory approach) was adopted for gathering data from a cross-section of staff in the selected teaching hospitals. Stratified-random sampling method was used to select the management staff while the purposive sampling method was used to choose the non-management staff that were directly affected by the policy. In this regard, the combination of both sampling methods hopefully gave representative responses and thereby allowed generalization of the subject matter on the various tertiary healthcare service providers. The generalisation could be possible because the entire staff (respondents) were guided by the same policies which affect organisational growth.

The primary source of data was used in collecting data. Specifically, the use of questionnaire was employed. The purpose of using questionnaire is to ensure the ease of comparison among variables and it is easy to understand. All specific variables or parameters were measured using items adapted from previous studies. The questionnaire comprises constructs such as career development (productivity domain, intrapersonal relations, interpersonal domain, leadership domain) on the dependent variable of organizational growth. Approximately, 400 copies of questionnaire were distributed the staff of the selected teaching hospitals, which completely take 02 months for the whole procedure. 384 copies of questionnaires were retrieved from the respondents. Out of 384 , only 377 copies of questionnaire were used to form the basis of our analysis as some respondents did not correctly fill them and it is not appropriate for interpretation of results.

For the research instrument, a structured questionnaire was adopted for collecting information from the staff of the sampled teaching hospitals. Sources of the instruments from the previous researches were utilized in creating the measurement scales for the constructs of this study. Thus, in measuring career development, five items were adapted and adopted from the study of Delery and Dotty (1996) and Tsui et al. (1997). While items for organisational growth were adapted from the study of Osibanjo Gberevbie and Abiodun (2014). The questionnaire was divided into two sections: (i) items on demographic variables and (ii) items based on the objectives of the study. The items in the questionnaire were adapted from extant literature. Adaptive approach is used for the selection of questions and the preparation of the questionnaire, a structured questionnaire drawn on a five-point Likert scale ranging from " 5 " indicating a strong agreement with the "1" statement indicates strong disagreement with the statement. The questionnaire was further validated with In-depth Interview. Specifically, the data collected were analysed using measurement (composite and average variance extracted) and structural models (Partial 
Least Square) to obtain results as recommended by Fornell and Lacker (1981).

\section{Results}

A total 400 copies questionnaires were distributed to respondents, 384 copies of questionnaires were collected from the respondents, 12 copies of the questionnaires were not completely filled and they were not appropriate for the interpretation of results. Therefore, 377 copies of the questionnaire were entered in Statistical Package for Social Sciences (SPSS) to perform the descriptive analysis. The

Table 1. Demographic characteristics of the respondents (source: Field work, 2018)

\begin{tabular}{|c|c|c|}
\hline $\begin{array}{l}\text { Demographic } \\
\text { Characteristics }\end{array}$ & & $\begin{array}{c}\text { Percentage } \\
(\mathrm{N}=377)\end{array}$ \\
\hline \multirow{2}{*}{ Gender: } & Male & $44.3 \%$ \\
\hline & Female & $55.7 \%$ \\
\hline \multirow{3}{*}{ Age: } & Below 35 years & $53.6 \%$ \\
\hline & $36-45$ years & $28.2 \%$ \\
\hline & 46years \& above & $18.2 \%$ \\
\hline \multirow{3}{*}{ Marital Status: } & Single & $41.8 \%$ \\
\hline & Married & $54.9 \%$ \\
\hline & Others & $3.3 \%$ \\
\hline \multirow{3}{*}{$\begin{array}{l}\text { Educational } \\
\text { Qualification: }\end{array}$} & $\mathrm{OND} / \mathrm{NCE}$ & $12.7 \%$ \\
\hline & B.Sc/HND & $66.8 \%$ \\
\hline & M.Sc/MBA & $20.5 \%$ \\
\hline \multirow{3}{*}{$\begin{array}{l}\text { Work } \\
\text { Experience: }\end{array}$} & $0-9$ years & $61.3 \%$ \\
\hline & $10-19$ years & $37.0 \%$ \\
\hline & Above 20 years & $1.7 \%$ \\
\hline \multirow{4}{*}{$\begin{array}{l}\text { Levels of } \\
\text { Management: }\end{array}$} & Top management level & $2.4 \%$ \\
\hline & $\begin{array}{l}\text { Middle management } \\
\text { level }\end{array}$ & $14.1 \%$ \\
\hline & Supervisory level & $23.5 \%$ \\
\hline & Lower management level & $44.0 \%$ \\
\hline
\end{tabular}

demographic survey/components of the respondents are depicted in Table 1. The female gender constituted $55.7 \%$ of the population; age 35 years and below represented $53.6 \%$. In addition, the marital status shows that the married are represented with $54.9 \%$ of the sample size. Furthermore, $66.8 \%$ of the respondents have obtained first degree (B.Sc/ HND) and in terms of relevance, response on educational status is said to be adequate for this survey. While average number of respondents have been on the job between one (1) to nine (9) years representing $61.3 \%$ of the respondents. The sample may be considered adequate with reference to the distributions of these characteristics as presented in Table 1.

\subsection{Model assessment}

This predicts the relationship between the dependent variable and maximize the explained variance, so partial least squares (PLS) was adopted as recommended by Fornell and Lacker (1981), Henseler and Chin (2010). Simultaneously, all hypotheses were tested by using smart PLS. PLS is causal modeling approach, that evolves two phases, i.e., evaluation of the measurement model (outer model), followed by the assessment of the structural model (inner model) (Henseler and Chin 2010). The outer model determined the relationship between constructive and related items, while the inner model defined the relationship between exogenous and endogenous constructs. Details of the convergent reliability using the Confirmatory Factor Analysis are presented in Table 2. The table indicated that the coefficient correlation is related and the conditions for checking the reliability of CFA were all met and significant.

Confirmatory factor analysis was conducted using AMOS to prove the construct validity by identifying the value of factor loading for each item when the fitness of the model was achieved. The construct validity was proven when there was no item had below than 0.60 value of factor loading. The results depict that the factor loadings of CFA and the major conditions used to examine the convergent validity as recommended by Fornell and Larcker (1981) and

Table 2. Result of convergent reliability using confirmatory factor analysis (source: Field work, 2018)

\begin{tabular}{|c|c|c|c|c|c|c|}
\hline Variables & Items & Loading & $\begin{array}{c}\text { Error } \\
\text { Variance }\end{array}$ & $\begin{array}{l}\text { Composite } \\
\text { Reliability }\end{array}$ & $\begin{array}{c}\text { Average } \\
\text { Variance } \\
\text { Estimated }\end{array}$ & No of Items \\
\hline \multicolumn{2}{|l|}{ Threshold } & $\geq 0.7$ & $\leq 0.5$ & $\geq 0.7$ & $\geq 0.5$ & \\
\hline \multirow{5}{*}{$\begin{array}{l}\text { Organizational } \\
\text { Growth }\end{array}$} & Career Development & 0.849 & 0.869 & 0.897 & 0.686 & 5 \\
\hline & Interpersonal Domain & 0.887 & 0.905 & 0.911 & 0.597 & 10 \\
\hline & Intrapersonal Domain & 0.780 & 0.807 & 0.849 & 0.532 & 10 \\
\hline & Leadership Domain & 0.882 & 0.871 & 0.903 & 0.610 & 10 \\
\hline & Productivity Domain & 0.881 & 0.882 & 0.906 & 0.548 & 10 \\
\hline \multicolumn{2}{|c|}{ Organizational Growth } & 0.801 & 0.274 & 0.883 & 0.716 & 5 \\
\hline
\end{tabular}


Table 3. Correlation Matrix (source: Field work, 2018)

\begin{tabular}{|c|l|c|c|c|c|c|c|}
\hline $\mathrm{S} / \mathrm{N}$ & \multicolumn{1}{|c|}{ Items } & 1 & 2 & 3 & 4 & 5 & 6 \\
\hline 1 & Career Development & $\mathbf{0 . 8 2 8}$ & & & & & \\
\hline 2 & Interpersonal Domain & 0.561 & $\mathbf{0 . 7 7 3}$ & & & & \\
\hline 3 & Intrapersonal Domain & 0.428 & 0.528 & $\mathbf{0 . 7 2 9}$ & & & \\
\hline 4 & Leadership Domain & 0.325 & 0.634 & 0.548 & $\mathbf{0 . 7 8 1}$ & & \\
\hline 5 & Productivity Domain & 0.763 & 0.604 & 0.579 & 0.386 & $\mathbf{0 . 7 4 0}$ & \\
\hline 6 & Organisational Growth & 0.497 & 0.545 & 0.653 & 0.480 & 0.490 & $\mathbf{0 . 8 0 9}$ \\
\hline
\end{tabular}

Bagozzi and Yi (1988) were met. Having run the validity and reliability tests, correlation matrix was presented in Table 3 to show the correlation coefficients of the variables.

The researchers used the Structural Equation Modelling analysis (version 22.0) to ascertain the relationship between the variables. The output results of structural model with standardized estimates and Fitness Index Measurement were presented in Figure 1 and Table 4.

The results illustrated in the Tables 4 and 5 demonstrate all path coefficients, standard error, T-values and corresponding p-values. Additionally, the R-squared index of the variables demonstrated a satisfactory level of
Table 4. Fitness Index Measurement (source: Field work, 2018)

\begin{tabular}{|c|c|c|c|}
\hline Fit Indices & Benchmark & Value & Results \\
\hline Chisq & $\mathrm{P}>0.05$ & 98.515 & Satisfied \\
\hline RMSEA & $<>0.80$ & .044 & Satisfied \\
\hline GFI & $>0.90$ & .941 & Satisfied \\
\hline AGFI & $>0.90$ & .969 & Satisfied \\
\hline CFI & $>0.90$ & .921 & Satisfied \\
\hline TLI & $>0.90$ & .963 & Satisfied \\
\hline NFI & $>0.90$ & .920 & Satisfied \\
\hline IFI & $>0.90$ & .955 & Satisfied \\
\hline
\end{tabular}

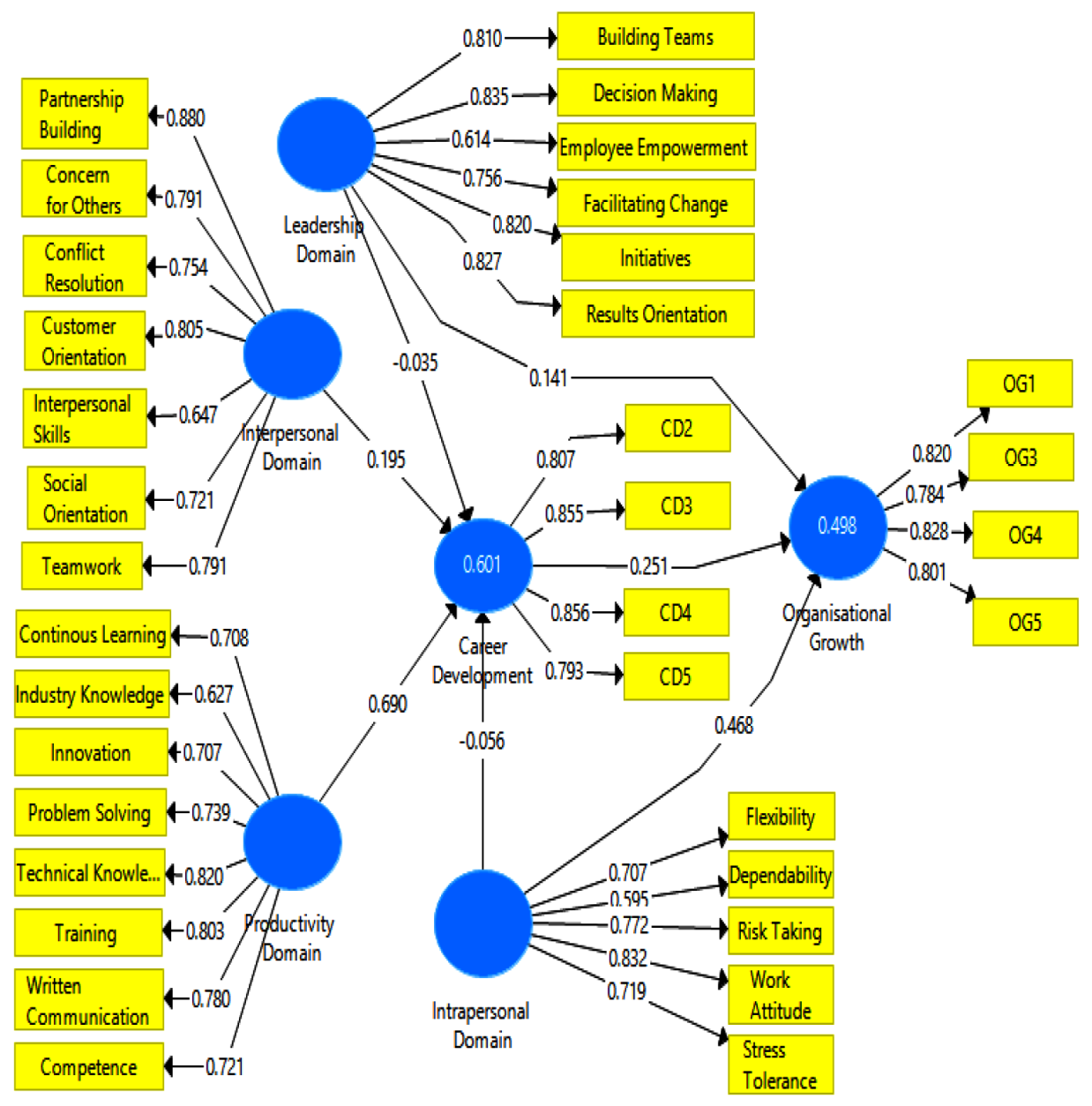

Figure 1. Output results of Structural model with standardized estimates 
Table 5. Estimates of covariance among exogenous variables

\begin{tabular}{|l|l|l|c|c|c|c|c|}
\hline & & & Estimate & S.E. & C.R. & P & Label \\
\hline Organisational Growth & $<---$ & Career Development & .251 & .057 & 3.015 & .003 & Sig. \\
\hline Career Development & $<---$ & Interpersonal Domain & .195 & .031 & 1.988 & .016 & Sig. \\
\hline Career Development & $<---$ & Intrapersonal Domain & -.056 & .057 & 1.211 & .311 & NS \\
\hline Organisational Growth & $<---$ & Intrapersonal Domain & .468 & .049 & 2.183 & .029 & Sig. \\
\hline Career Development & $<---$ & Leadership Domain & -.035 & .042 & 0.601 & .230 & NS \\
\hline Organisational Growth & $<---$ & Leadership Domain & .141 & .040 & 1.975 & .023 & Sig. \\
\hline Career Development & $<---$ & Productivity Domain & .690 & .033 & 3.882 & .008 & Sig. \\
\hline
\end{tabular}

Note: C.R. $=$ Critical Ratio; S.E. $=$ Standard Error; ${ }^{\star}$ significant at 0.05 .

predictability, which exceeded the suggested starting point of 0.1 . The R-square value of 0.498 which exceed the form 0.1 as suggested by Falk and Miller (1992). The PLSSEM model represents the relationships between variables and the hypothetical decision was demonstrated as estimates of covariance among exogenous variables in Table 5.

\subsection{Test of hypothesis and discussion}

Hypothesis 1 investigates the effect of leadership domain on organizational growth. According to Table 4 and Figure 1, the standardized direct (path) effect of leadership domain on organizational growth is 0.141 (approximately 14\%), its standard error is 0.040 . This is highly significant at $p$ $<0.023$. Hence, hypothesis 1 was accepted. This implies that leadership domain has significant positive effect on organizational growth among the workforce in health sector. This result corroborated the finding from Muhammad et al. (2016) where significant positive effect of leadership style on employees' engagement was established. Similarly, Armstrong (2011) had earlier found positive relationship between managerial style and performance civil servant. Likewise, Brousseau et al. (2012), Asif et al. (2011), Lam et al. (2013) and Mishra and Sachan (2012) had found positive interaction between leadership style and employees' commitment in their different studies.

Hypothesis 2 concerns the influence of intrapersonal domain on organizational growth. As shown in Table 4 and Figure 1, intrapersonal domain has positive influence on organizational growth to the extent of standardized direct path of 0.468 (approximately 47\%), standard error of 0.049 , which is significant at $\mathrm{p}<0.029$. This however, informed the acceptance of hypothesis 2 . This finding indicated that intrapersonal domain (based on reasoning, affection, cohesion, care, support, consistent interactions, or some other type of social assembly) has positive effect on organizational growth among health sector workers. This outcome is in line with the finding of Tareef (2012) in his study on mentoring and career development of Higher Education Faculty Members. Moreso, Ovidiu (2013) established positive effect of career development on the performance of production workers. These scholars further stated that close association between individuals who share common interests propel optimum performance. Significant number of studies had likened the concept of intrapersonal relationship with the concept of mentoring and coaching (Adeniji and Osibanjo 2012). However, earlier studies such as Tareef (2012) and Vander-Sluis and Poell (2003) found positive interaction between cognitive reasoning and employees' job performance.

Hypothesis 3 examines the relationship between career development and organizational growth. As indicated in Table 4 and Figure 1, there is a positive interaction between career development and organizational growth, the standardized path coefficient between career development and organizational growth revealed 0.251 , its standards error was 0.057 and the critical ratio was 3.015 with $\mathrm{p}<0.05$ level of significance. This prompted the acceptance of hypothesis 3. This outcome shows that career development impact positively on organizational growth of the health sector. Though, some of the employees agitated that career development practice should consistently be perceived competitive, workable, fair and satisfying their needs. Hence, the employees will be motivated to be more effective by achieving the organizational goals when they have clear picture of their career paths, provided with proper career development-based activities as well as they are informed and really understand the procedures and policies of career development. The results obtained from the survey is similar to support the related previous researches (Salau et al. 2018, Muhammad et al. 2016, Osibanjo et al. 2014, Mishra and Sachan 2012, Gachunga and Wamoto 2012) although they were conducted in different perspective. Expectedly as argued in the literature, management of career development is seen as one of the critical factors in promoting organizational growth (Andrew and Kent 2007, Tareef 2012, Adeniji and Osibanjo 2012). This finding is consistent with finding from Osibanjo et al. (2014), where positive correlation was established between career management practices and organizational growth of the Nigerian Banking Industry. Salau et al. (2018) had earlier found positive relationship between career development and performance of selected Fast-Moving Consumer Goods (FMCGS) firms in Nigeria. Similarly, Tareef (2012) also found positive effect of career 
development of Higher Education Faculty Members. In addition, Zin et al. (2013) established positive effect of career development on the performance of production workers in japanese companies.

Responses from the IDI conducted for the staff and management of sampled teaching hospitals

The results from this quantitative data was also validated with the use of in-depth interview (qualitative). The responses indicate a perception of career management strategy, with many attributing this expectation to their commitment and satisfaction. The responses were described verbatim as thus:

Career development comes in many forms, but it's important that its not be relegated only to annual performance reviews. I strongly believe that employees want their employers to suggest ways they can improve. By doing so, my hospital consistently addresses two critical aspects of talent management: employee development and retention rates.

$$
\text { (Hospital A - tenure of } 8 \text { years). }
$$

As a member of management board, we consistently engage staff (both casual and full staff) with short career conversations frequently and iteratively, rather than waiting until the annual development review. "When we interview people, we want to hear all about who they are, what they've done, what they love, their talents, what they're interested in... and what they're not interested in. This has actually helped us to grow beyond expectation...

\section{(Hospital Accountant - tenure of 10 years).}

Sparingly, managers and supervisors are working assiduously towards the fulfilment of these expectations. Though at the beginning, I developed an anxiety over my performance potential and competency... But was helped by a supportive and caring superior who assist me in becoming a productive employee.

\section{(Hospital Admin staff - tenure of 6 years).}

As a manager will consistently need to meet expectations for transparency, from workplace evaluations and career plans to the five-year strategy for the business. Individuals need to take ownership of their careers but will need help to do that. Sometimes... when advancement opportunities in the hospitals are limited, I feel impatient, dissatisfied and frustrated.

\section{(Service Manager - tenure of 4 years).}

Sincerely... the hospital gives employees the opportunity to evaluate their progress toward career goals with supervisors... We try to promote career conversation as employees learn more, grow, evolve and take on more duties and responsibilities. Make clear decisions about what data should be available to employees - and remember that to keep people happy, the default position should be transparency.

$$
\text { (HR Manager - tenure of } 7 \text { years). }
$$

First of all, I don't make a goal just for the sake of making it. It's hard to do, but successful goal setting is vital to career development. I make goals that truly resonate with me, because I am going to need drive and passion to stay on the career path for as long as it takes. I can say it anyday-anytime that career planning process in my hospital has been a joint process between the individual and the organization.

(Hospital Admin Staff - tenure of 12 years).

Though... career planning is a burden but we are rewarded and equipped to assist employees through counselling and encouragement. As supervisors, we are always aware career development opportunities without internal career paths/opportunities may only work to prepare and develop our employees to take jobs in other organizations. We used to believe employees leave because of their managers. Now it seems they leave because of their careers.

$$
\text { (Supervisor - tenure of } 10 \text { years) }
$$

\section{Conclusions and managerial implications}

Talent has never been scarcer or costlier, so organizations are naturally turning their attention to internal development of skills (to meet their needs) and careers (to retain their best). This has always been the biggest opportunity for HR to demonstrate business alignment, strategic contribution, and front-line support. Traditionally, employees judge their career progression through changes in grade or title. But most organizations including the health sector, cannot offer lots of opportunities for upward progression. It is more difficult to get promoted today than it was five years ago. Capability development in the selected health care organisations focused on an employee's progress in gaining skills, knowledge, and experience. These are achievements and personal attributes that often contribute to their success. Capability development creates a more flexible and higher-quality workforce. At the same time, it increases employee career satisfaction. The study has provided insight for improving employee effectiveness via investing in the development of skills which improves their experiences; promoting them as at when due without victimization and rewarding them based on their achievements and recognizing the values added to the organization. Like dressing for success, employees also have to train for success; and when companies invest in employees, employees invest in companies - with satisfaction, engagement and longevity.

To create a culture of growth, career development needs to be a partnership between the organisation and employee. If an organisation wants to engage its employees, the culture 
needs to support their professional growth. Having senior leaders articulate the value of career development is critical. As role models, the stories they tell of their own career development are incredibly powerful. By taking collective ownership, they create a proactive brokerage for sharing talent across the organisation. As a result of this, organisations must learn to provide employees with the training and support to take ownership for their career development. By implications, the training managers must also be encouraged to have effective career conversations. This implies that there must be need to have an ongoing dialogue between managers and employees in the selected sector to ensure increased retention rate.

Moreover, the study has charted a path for the management team in the area of personnel career enhancement to put in place plans for all categories of staff to ensure they are adequately remunerated with rewards and promotions and be given a fair opportunity to develop their skills via career development and advance without partiality or favouritism which impact on their effectiveness and in the long run growth and survival of the organization. Not only that the study had been an eye opener for management in the health sector, that, for organizations to grow and continue to survive especially in this economic recession, employee's effectiveness needs to be taken seriously especially the factors responsible for these as tested in this study.

The objective for the companies should be to ensure a pool of highly competent and skilled individuals. And focus should be placed on compiling career paths, identifying competencies with the appropriate behavioural skills, succession planning and manpower planning. The findings suggest a variety of development activities attractive to staff, including workshops to develop tech skills, learning to develop managerial competencies, career planning workshops, tuition reimbursement planning and job rotation within different divisions and functional areas in the company. "Organizations that have managerial succession planning programmes at various levels of the organization seem to communicate to the employees the value they place on development as well as internal promotion". Additionally, formal and informal mentoring and job shadowing opportunities are attractive for those employees seeking to develop their careers while also expanding their social networks.

\section{Acknowledgements}

We sincerely appreciate Covenant University Management for providing the platform to contribute to the body of knowledge and for sponsoring the publication of this paper. We say thank you.

\section{References}

Adekola B (2011) Career planning and career management as correlates for career development and job satisfaction. A case study of Nigerian bank employees. Australian Journal of Business and Management Research, 2.

Adeniji AA, Osibanjo AO (2012) Human resource management: Theory \& practice. Lagos. Pumark Nigeria Limited.

Adeniji A, Falola H, Salau O (2014) A modelling relationship between work satisfaction and faculty performance in the Nigerian private universities. European Scientific Journal 10 (32): 63-80.

Adeniji AA, Salau O, Awe K, Oludayo O (2018) Survey data on organisational climate and job satisfaction among academic staff in some selected private universities in Southwest Nigeria. Data in Brief (Elsevier), Science Direct, Vol. 19 (pp. 1688-1693). https://doi.org/10.1016/j.dib.2018.06.001

Adeniji AA, Akinnusi DM, Falola HO, Ohunakin F (2017) Administration of retirement benefits in Nigeria: Periscoping the effect on retirees. International Journal of Applied Business and Economic Research 15 (17): 1-15.

Andrew DPS, Kent A (2007) The impact of perceived leadership behaviors on satisfaction, commitment, and motivation: An expansion of the multidimensional model of leadership. International Journal of Coaching Science 1 (1): 35-56.

Armstrong M (2011) A handbook of human resource management practice (12th ed). Kogan Page Limited: United Kingdom.

Asif K, Muhammad H, Asim SL, Mohammad AK, Syed JAB, Rabia A (2011) Emotional intelligence and employee participation in decision making. African Journal of Business Management 5 (12): 4775-4781.

Bagozzi R, Yi Y (1988) On the evaluation of structural equation models. Journal of the Academy of Marketing Sciences 16: 74-94. https://doi.org/10.1007/BF02723327

Blau P (1964) Power and exchange in social life. NY: John Wiley \& Sons.

Bombuwela PM, De Alwis AC (2013) Effects of glass ceiling on women career development in private sector organizations Case of Sri Lanka. Journal of Competitiveness 5 (2): 3-19. https://doi.org/10.7441/joc.2013.02.01

Brousseau KR, Driver, MJ, Eneroth, K, Larsson, R (2012) Career pandemonium: Realigning organizations and individuals. Academy of Management Executive 10: 52-64. https://doi. org/10.5465/ame.1996.3145319

Delery JE, Doty DH (1996) Modes of theorizing in strategic human resource management: Test of universalistic, contingency, and configurational performance predictions. Academy of Management Journal 39: 802-835. https://doi. org/10.5465/256713

Falk RF, Miller NB (1992) A primer for soft modeling. University of Akron Press, Akron.

Flexer RW, Baer RM, Luft P, Simmons TJ (2005) Transition planning for secondary students with disabilities. Upper Saddle River, NJ: Pearson/Merrill-Prentice Hall. 
Fornell CD, Lacker DF (1981) Evaluating structural equation models with unobservable variables and measurement error. Journal of Marketing Research 18: 39-50. https://doi. org/10.1177/002224378101800104

Gachunga HG, Wamoto O (2012) The effect of career development activities on employee performance: a case study of world agroforestry centre. International Journal of Knowledge, Culture and Change Management, 11 (6): 121-142. https://doi.org/10.18848/1447-9524/CGP/v11i06/50215

Henseler J, Chin WW (2010) A comparison of approaches for the analysis of interaction effects between latent variables using partial least squares path modeling. Structural Equation Modeling: A Multidisciplinary Journal 17 (1): 82-109. https:// doi.org/10.1080/10705510903439003

Ibidunni S, Omotayo OA, Adeniji AA, Salau OP, Falola HO (2016) Talent retention and organizational performance: A competitive positioning in Nigerian banking sector. Periodica Polytechnica Social and Management Sciences 24 (1): 1-13. https://doi.org/10.3311/PPso.7958

Kalejaiye P, Sokefun E, Adewusi A (2015) Leadership and human resource development in Nigeria: factors for national development. The Nigerian Journal of Sociology and Anthropology 13 (1): $127-144$.

Lam N, Dyke L, Duxbury L (2013) Career development in bestpractice organizations: critical success factors. Optimum. The Journal of Public Sector Management 29 (4): 22-30.

Law B, Watts AG (2015) Careers education. In: Hooley T, Barham L. Career development policy and practice: The Tony Watts Reader. Stafford: Highflyers, pp. 71-78.

Maimunah I (2016) Cultural values and career goal of Gen-X and Gen-Y: A conceptual framework. International Journal of Global Business and Management Research 8 (2): 1-18 (ERA).

Maimunah I, Atikah NR (2016) Influence of cultural values on career goal of an intergenerational workforce in a Malaysian industrial corporation. European Journal of Business and Social Sciences 4 (12): 46-57.

Merchant Jr RC (2010) The role of career development in improving organizational effectiveness and employee development. Florida Department of Law Enforcement.

Mishra B, Sachan D (2012) Career management: A key driver of performance and productivity. International Journal of Management Research and Review 2 (8): 1334-1341.

Muhammad S, Abdul-Rahman M, Muh J, Syamsu N (2016) The effect of career development and working discipline towards working satisfaction and employee performance in the Regional Office of Ministry of Religious Affairs in South Sulawesi. International Journal of Scientific and Technology Research 5 (3): 51-57.

Nairaland (2018) https://www.nairaland.com/1820338/20-bestmedical-hospitals-nigeria

Oduma C, Were S (2014) Influence of career development on employee performance in the public university. International Journal of Social Sciences Management and Entrepreneurship, 1-16.

Ohunakin F, Adeniji AA, Akintayo DI (2017) Human resource management practices and organisational commitment: employees' perspective in the Nigerian hospitality sector. New Trends and Issues Proceedings on Humanities and Social Sciences 4 (10): 246-255 www.prosoc.eu
Ohunakin F, Adeniji AA, Oludayo OA, Osibanjo AO (2018a) Survey dataset on leadership styles and job satisfaction: the perspective of employees of hospitality providers. Data in Brief 19: 2178-2188. https://doi.org/10.1016/j.dib.2018.06.033

Ohunakin F, Adeniji A, Oludayo O, Osibanjo O (2018b) Perception of frontline employees towards career growth opportunities: implications on turnover intention. Business: Theory and Practice 19: 278-287. https://doi.org/10.3846/btp.2018.28

Oladejo EI (2014) Evaluation of challenges of facilities management in tertiary healthcare institutions in South East Nigeria. Published PhD Dissertation, Nnamdi Azikiwe University Awka, Anambra State, Nigeria.

Oni-Ojo EE, Salau OP, Dirisu JI, Waribo YJ (2015) Incentives and job satisfaction: Its implications for competitive positioning and organizational survival in Nigeria manufacturing industries. American Journal of Management 15 (2): 75-87.

Osibanjo AO, Salau OP, Falola HO (2014) Modeling the relationship between motivating factors; Employee' retention; and job satisfaction in the Nigerian banking industry. Journal of Management Policies and Practices 2 (2): 63-83.

Osibanjo AO, Gberevbie D, Abiodun JO (2014) Career development as a determinant of organizational growth: Modelling the relationship between these constructs in the Nigerian banking industry. American International Journal of Social Science 3 (7): 64-76.

Osibanjo AO, Abiodun AJ, Salau OP, Adeniji AA, Falola HO, Alimi II (2018) Job design and behavioural outcome of employees in agricultural research training, Ibadan, Nigeria. Data in Brief (Elsevier), Science Direct, 19, 1880-1887. https://doi. org/10.1016/j.dib.2018.06.073

Ovidiu ID (2013) Employee motivation and organizational performance. Review of applied socio- economic research 5 (1): 53.

Rostami H, Bahramzadeh H, Saeidi P (2015) The relationship between employee's empowerment with job performance at the Red Crescent Society of North Khorasan. International journal of Basic Science \& Applied Research 4 (6): 320-322.

Salau OP Adeniji AA, Oyewunmi EA (2014) Relationship between elements of job enrichment and organizational performance among the Non-academic staff in Nigerian Public Universities. Management \& Marketing 12 (2).

Salau O, Worlu R, Osibanjo A, Adeniji A, Oludayo O, Falola H (2018) Survey data on work environments and productivity of academic staff of selected public universities in Nigeria. Data in Brief (Elsevier), Science Direct 19: 1912-1917. https://doi. org/10.1016/j.dib.2018.06.074

Salau O, Osibanjo A, Adeniji A, Ojebola O, Oludayo O, Falola H, Atolagbe T (2018) Datasets on employee value proposition (evp) and performance of selected fastmoving consumer goods (FMCGs) firms in Nigeria. Data in Brief (Elsevier), Science Direct 19: 1907-1911. https://doi.org/10.1016/j. dib.2018.06.027

Sahoo CK, Mishra S (2012) A framework towards employee engagement: The PSU Experience. ASCI Journal of Management 42 (1): 94-112.

Sheppard G (2016) Work-life balance programs to improve employee performance. Walden University Scholar Works, 1-329. 
Sultana RG (2013) Career management skills: Assessing for learning. Australian Journal of Career Development 22: 82-90. https://doi.org/10.1177/1038416213496759

Tareef AB (2012) The relationship between mentoring and career development of higher education faculty members. College Student Journal, The University of Jordan (pp. 703-710).

Tsui AS, Pearce JL, Porter LW, Tripoli AM (1997) Alternative approaches to the employee-organization relationship: Does investment in employees pay off? Academy of Management Journal 40: 1089-1121. https://doi.org/10.5465/256928

Vander-Sluis LEC, Poell RF (2003) The impact on career development of learning opportunities and learning behaviour at work. Human Resource Development 14: 159-179. https:// doi.org/10.1002/hrdq.1058
Wahyuni N (2016) Effect of education and training, career development and job satisfaction of employee performance at the department of education office of Gowa. Journal of Education and Vocational Research 7 (10): 14-20.

Zhang Y (2012) The impact of performance management system on employee performance. Analysis with WERS 2004 (pp. 1-57).

Zin LM, Shamsudin FM, Subramaniam C (2013) Investigating the influence of job rotation on career development among production workers in Japanese companies. International Journal of Business and Society 14 (1): 135-148. 